\title{
Adolescent gynae clinic - need of the day: a prospective study at a tertiary care centre
}

\author{
Anita Jain, Dibya Singh*
}

Department of Obstetrics and Gynaecology, Saraswati Medical College, Unnao, Uttar Pradesh, India

Received: 26 February 2019

Accepted: 02 April 2019

\section{*Correspondence:}

Dr. Dibya Singh,

E-mail: drds.31080@gmail.com

Copyright: (c) the author(s), publisher and licensee Medip Academy. This is an open-access article distributed under the terms of the Creative Commons Attribution Non-Commercial License, which permits unrestricted non-commercial use, distribution, and reproduction in any medium, provided the original work is properly cited.

\begin{abstract}
Background: To study common gynaecological problems in adolescent girls and to establish the need of adolescent clinic.

Methods: A prospective study was conducted including 250 adolescent girls attending gynaecology OPD. Girls were evaluated by detailed history, thorough clinical examination and investigations such as haemogram, coagulation profile, hormonal assays, ultrasound examination of abdomen and pelvis, as and when indicated.

Results: Majority of girls had complaints related to menstrual disorders i.e. 58.3\%. Most common causes of menstrual abnormalities were dysfunctional uterine bleeding $(42.85 \%)$ followed by polycystic ovarian syndrome (26.19\%) and pelvic inflammatory disease $(15.47 \%)$.

Conclusions: Problems are specific to this age group, setting up of separate adolescent clinics is desirable of efficient management where they can be provided adequate privacy to discuss their problems openly.
\end{abstract}

Keywords: Adolescent, Adolescent clinic, Gynaecological problems, Menstrual disorder

\section{INTRODUCTION}

Adolescence -"Puberty to maturity"-A physical, neural, cognitive and socio emotional transformative phase of life."

Adolescence is a period of life with specific health and developmental needs and rights. It is also a time to develop knowledge and skills, learn to manage emotions and relationships and acquire attributes and abilities that will be important for enjoying the adolescent year assuming the adult roles. According to WHO, age limit of adolescence is $10-19$ years, but changes may begin before and continue after this age group. ${ }^{1}$

In India as per census 2011, adolescent population (10-19 years) is 253.2 million, constituting $20.9 \%$ of the total population. $^{2}$
It is important to have a thorough knowledge of normal changes occurring in this age group as also of the demographic pattern of distribution and prevalence of specific gynaecological problems in order to offer quality medical/surgical services to this group of patients. Gynaecological problems of adolescent occupy a special space in spectrum of gynaecological disorder of all ages. This is because the physical natures of the problems are so unique, special and specific for the age group and also because of the associated social and psychological factors. Adolescent gynaecology is the subgroup of gynaecology which is yet to be explored optimally. Nowadays, significant numbers of adolescent girls have started attending OPD. With this preface, a study has been done to find the gynaecological problems of adolescents attending gynae clinics and to establish the need of today-Adolescent gynae clinic. 


\section{METHODS}

A prospective study was conducted in the department of obstetrics and gynaecology at Saraswati Medical College, Unnao, Uttar Pradesh India, including 250 adolescent girls attending gynaecology OPD from January 2017 till December 2018.

\section{Inclusion criteria}

- Adolescent females between the age group of 11 to 19 years.

\section{Exclusion criteria}

- Not willing to participate in the study

- Medical and surgical problems not relating to Gynaecology.

An informed consent was taken after explaining our objective. 250 adolescent girls were evaluated by taking detailed history and doing thorough clinical examination including height, weight, general and physical examination evaluating secondary sexual characters. Sign and symptoms of hyperandrogenism (acne, hirsutism), obesity, hyperprolactenemia and thyroid disorder were looked for where appropriate. It was important to provide privacy and friendly environment in order to make patient comfortable while discussing confidential information.

Investigations such as haemogram, coagulation profile, hormonal assays (FSH, LH, Prolactin and Thyroid profile), ultrasound examination of abdomen and pelvis were done as and when indicated.

\section{RESULTS}

A total of 250 adolescent patients were evaluated for the present study belonging to age group of 10 to 19 years. Out of these 10 girls were having complaints not related to gynaecology so they were excluded from the study group. Table 1 shows age distribution of the adolescent girls attending our OPD. In our study $95.5 \%$ patients were from late adolescent age group i.e. 15-19 yrs.

Table 1: Age distribution $(n=240)$.

\begin{tabular}{|lll|}
\hline Age (years) & Number & Percentage \\
\hline $10-14$ & 11 & 4.5 \\
\hline $15-19$ & 229 & 95.5 \\
\hline
\end{tabular}

Although majority of adolescent girls in our study were unmarried (79\%), 21\% were married, it shows teenage marriages are still prevalent in our country, especially in rural area (Table 2).

As seen in Table 3, majority of girls had complaints related to menstrual disorders i.e. $58.3 \%$. This was followed by leucorrhoea i.e. $18.3 \%$, follicular cysts \& ovarian mass $(6.3 \%)$, pain in abdomen $(3.8 \%)$, urinary tract infection $(3.3 \%)$, teenage pregnancies $(3.3 \%)$, breast problems $(3.3 \%)$. Other uncommon conditions (3.3\%) reported were vulval infections (4 cases), injury of genital area ( 2 cases), and one case each of precocious puberty $\&$ obesity. In our study $20(14.3 \%)$ girls were found to be amenorrhic (Table 4).

Table 2: Marital status $(\mathrm{n}=\mathbf{2 4 0})$.

\begin{tabular}{|lll|}
\hline Marital status & Number & Percentage \\
\hline Unmarried & 189 & 79 \\
\hline Married & 51 & 21 \\
\hline
\end{tabular}

Table 3: Gynaecological problems amongst adolescent girls $(n=240)$.

\begin{tabular}{|lll|}
\hline Complaints & Number & Percentage \\
\hline Menstrual problems & 140 & 58.3 \\
\hline Leucorrhoea & 44 & 18.3 \\
\hline Follicular cyst/ovarian mass & 15 & 6.3 \\
\hline Teenage pregnancy & 8 & 3.3 \\
\hline Urinary tract infection & 8 & 3.3 \\
\hline Breast problems & 8 & 3.3 \\
\hline Pain abdomen(PID) & 9 & 3.8 \\
\hline Others & 8 & 3.3 \\
\hline
\end{tabular}

Table 4: Type of menstrual problems $(n=140)$.

\begin{tabular}{|ll|l|}
\hline Complaints & Number & Percentage \\
\hline Amenorrhea & 20 & 14.3 \\
\hline Dysmenorrhea & 36 & 25.7 \\
\hline Menstrual irregularity & 84 & 60 \\
\hline
\end{tabular}

It was worth noting causes of primary amenorrhoea. Out of 8 girls, 3 were having imperforate hymen, one case of mullerian agenesis and in 4 cases no abnormality could be found so they were taken as cases of delayed menarche (Table 5).

Table 5: Causes of amenorrhoea $(n=20)$.

\begin{tabular}{|lll|}
\hline Complaints & Number & Percentage \\
\hline Primary amenorrhoea & $\mathbf{8}$ & $\mathbf{1 0 0}$ \\
\hline Imperforate hymen & 3 & 37.5 \\
\hline Mullerian agenesis & 1 & 12.5 \\
\hline Delayed menarche & 4 & 50 \\
\hline $\begin{array}{l}\text { Secondary } \\
\text { amenorrhoea }\end{array}$ & $\mathbf{1 2}$ & $\mathbf{1 0 0}$ \\
\hline PCOS & 9 & 75.0 \\
\hline Stress & 1 & 8.3 \\
\hline Anorexia nervosa & 1 & 8.3 \\
\hline Immature HPO axis & 1 & 8.3 \\
\hline
\end{tabular}

Among other menstrual problems $25.7 \%$ girls presented with dysmenorrhea (Table 6) and $60.0 \%$ girls presented with irregular menses (Table 7) out of which oligomenorrhea accounted for $47.6 \%$ followed by metrorrhagia (28.6\%) and menorrhagia (23.8\%). 
Table 6: Types of dysmenorrhea $(n=36)$.

\begin{tabular}{|lll|}
\hline Types & Number & Percentage \\
\hline Dysmenorrhoea & 36 & 100 \\
\hline Primary & 21 & 58.3 \\
\hline Secondary & 15 & 41.7 \\
\hline
\end{tabular}

Table 7: Types of menstrual irregularities $(n=84)$.

\begin{tabular}{|lll|}
\hline Types & Number & Percentage \\
\hline Irregular menses & 84 & 100 \\
\hline Menorrhagia & 20 & 23.8 \\
\hline Metrorrhagia & 24 & 28.6 \\
\hline Oligomenorrhoea & 40 & 47.6 \\
\hline
\end{tabular}

While analysing causes of menstrual irregularity, it is evident that most common cause is dysfunctional uterine bleeding $(42.85 \%)$ followed by polycystic ovarian syndrome $(26.19 \%)$ \& pelvic inflammatory disease $(15.47 \%)$. Less common causes include hypothyroidism, hyperprolactenemia, anorexia nervosa, stress, fibroid uterus, endometrial polyp, tuberculosis \& tubo-ovarian masses (Table 8).

Table 8: Causes of menstrual Irregularity $(n=84)$.

\begin{tabular}{|lll|}
\hline Causes & No. & Percentage \\
\hline Dysfunctional uterine bleeding & 36 & 42.85 \\
\hline Polycystic ovarian syndrome & 22 & 26.19 \\
\hline Pelvic inflammatory disease & 13 & 15.47 \\
\hline Hypothyroidism & 4 & 4.76 \\
\hline Fibroid/ polyp & 3 & 3.57 \\
\hline Hyperprolactinemia & 2 & 2.38 \\
\hline Anorexia nervosa/ stress & 2 & 2.38 \\
\hline Tuberculosis/TO mass & 2 & 2.38 \\
\hline
\end{tabular}

\section{DISCUSSION}

Present study shows that number of girls reporting in gynaecological clinic in early adolescent age is very less i.e. only $4.5 \%$. Probable cause for this may be unawareness among the population of the need for medical management of gynaecological problems at this age. Other cause may be that girls are still shy and apprehensive to discuss their problems.

Analysing the data, we find that teenage marriages are still prevalent in our society, accounting for $21 \%$ of patients in our study.

Looking at the problems faced by adolescent girls, disturbances of menstruation are the most common complaints bringing them to gynaecological clinic $(58.3 \%)$. Goswami $\mathrm{S}$ et al have also found similar incidence $(58 \%)$, however, Ramaraju et al have found in their study even higher number of girls (74\%) complaining of menstrual abnormalities. ${ }^{3,4}$ In the present study, $5.7 \%$ girls presented with primary amenorrhoea. 3 cases were having imperforate hymen and were treated by surgery. One girl was found to have mullerian agenesis, whereas in 4 girls, no abnormality was found so they were taken as cases of delayed puberty and were counselled accordingly. Incidence of primary amenorrhoea was found to be $11.1 \%(8 / 72)$ by Goswami $\mathrm{S}$ et al, 9.4\% (7/74) in the study done by Ramaraju et al andonly $3 \%$ by Bhalerao-Gandhi A et al. ${ }^{3-5}$

Secondary amenorrhoea accounted for $8.6 \%$ of cases in our study \& causes include Polycystic ovarian syndrome (9 girls), \& 1 case each of stress, anorexia nervosa \& immature hypothalamus-pituitary-ovarian axis. Goswami $S$ et al have found $18 \%$ (13/72) incidence, though causes differed. ${ }^{3}$ There was one case of premature ovarian failure at so early age in their study.

Dysmenorrhoea was a fairly common problem among adolescent girls $(25.7 \%)$, of these primary dysmenorrhoea accounted for $58.3 \%$ of cases and secondary dysmenorrhoea was seen in $41.7 \%$ cases. Infection being the most common cause responsible for secondary dysmenorrhea, they were treated by antibiotics. For primary dysmenorrhoea, girls were counselled in detail and were prescribed antispasmodics. Ramaraju et al have found that $19 \%$ adolescents presented with dysmenorrhoea whereas Goswami S et al found 7\% adolescents presenting with dysmenorrhoea. ${ }^{4,3}$

Among the girls presenting with menstrual irregularities, oligomenorrhoea was most common presentation accounting for $47.6 \%$ of cases followed by metrorrhagia $(28.6 \%) \quad \&$ menorrhagia (23.8\%). Ramaraju H.E.et al have reported oligomenorrhoea in $45.45 \%$ of cases \& menorrhagia in $34 \%$ of cases, whereas in the study done by Goswami $\mathrm{S}$ et al, oligomenorrhoea was the presentation in $56.86 \%$ of girls, followed by menorrhagia \& metrorrhagia, together accounting for $33.3 \%$ of cases. ${ }^{4,3}$

Analysing the causes of menstrual abnormalities, we found DUB was responsible for as many as $42.8 \%$ of cases, as vast majority of abnormal bleeding in adolescents is caused by immaturity of HypothalamicPituitaty-Ovarian axis as noted by Dangal G. ${ }^{6}$ Other causes found were PCOS (26.2\%) followed by PID $(15.4 \%)$. Less common causes include hypothyroidism, hyperprolactenemia, uterine fibroids, endometrial polyps, tuberculosis, anorexia nervosa \& extreme physiological stress.

Of the remaining 100 patients, $44(18.3 \%)$ reported with complaint of discharge per vagina. Leucorrhea can be physiological or pathological. Increased level of endogenous estrogen lead to marked overgrowth of the endocervical epithelium, which may encroach outward and produce ectocervical erosion leading to excess discharge. ${ }^{7}$ It was found that majority of them i.e. 28 $(63.6 \%)$ were having normal physiological discharge for which they need to be counselled and educated only. However, 16(36.4\%) were having infection and needed 
treatment along with proper guidance regarding menstrual hygiene. Ramaraju et al found vaginal discharge was second commonest complaints in $17 \%$ cases. ${ }^{4}$ All of them had physiological leucorrhea which responded to counseling. Goswami S et al, found $19.35 \%$ girls presenting with leucorrhea. ${ }^{3} 10$ girls came with ultrasound report showing a small ovarian cyst (follicular cyst) as incidental finding and needed detailed counseling to dispel their apprehension. Three patients had ovarian cysts, one needed surgery, two were kept under observation. Two other girls had TO mass and were treated accordingly. Goswami $\mathrm{P}$ et al, found $5.33 \%$ adolescent girls had physiological cyst of ovary. ${ }^{8}$ Functional cysts are the most frequently observed cystic masses of the ovary accounting for $20-50 \%$ ovarian tumours during childhood and adolescence (Kzlowski $\mathrm{KJ}){ }^{9}$

We had $8(3.3 \%)$ cases of teenage pregnancy, out of which 2 girls had spontaneous abortion. Similar result was found by Goswami S et al, 4.03\% (5/124) girls with teenage pregnancy. ${ }^{3}$ Teenage pregnancies, being prone to various complications, need to be given special care and should be counselled accordingly. Teenage girls should be educated regarding contraception so that pregnancy could be planned at proper age.

Eight $(3.3 \%)$ girls reported with breast problems, of which four girls had simple mastalgia of growing age. They were counselled and were given analgesics. 3 girls were diagnosed with fibroadenoma breast, one needing surgery for its size, other two were kept under observation. One girl was brought by parents for consultation regarding developing breast nodule and needed proper counselling. Samarth $\mathrm{S}$ et al, found symptoms related to breast were present in $15.6 \%$ adolescents. ${ }^{10}$ Sonmenz $\mathrm{K}$ et al, states the most frequent breast complaint was palpation of a breast lump. ${ }^{11}$ Most common histology of breast lump was fibroadenoma. 8 $(3.3 \%)$ patients were diagnosed with urinary tract infection and $9(3.8 \%)$ had pelvic infections. They were treated with antibiotics and were educated regarding proper menstrual hygiene and safe sex. Goswami $\mathrm{P}$ et al have also reported similar results, urinary tract infection in $4 \%$ and pelvic inflammatory disease in $8 \%$ of girls. ${ }^{8}$

\section{CONCLUSION}

Adolescents present with myriad of gynaecological problems. Over last few years adolescent gynaecology has emerged as a sub-speciality. One should have empathy, friendliness and non-judgemental attitude towards girls at this tender age of adolescence.

Since problems are specific to this age group, setting up of separate adolescent clinics is desirable of efficient management where they can be provided adequate privacy and congenial environment to discuss their problems openly. We need to give special emphasis to the adolescent population regarding their menstrual hygiene, sex education and contraception as today's youth is tomorrow's worker, entrepreneur, parent, active citizen and indeed leader. However the total number of girls is small in our study and further studies are required to be undertaken to establish the "NEED".

Funding: No funding sources

Conflict of interest: None declared

Ethical approval: The study was approved by the Institutional Ethics Committee

\section{REFERENCES}

1. Sheil O, Turner M. Adolescent Gynaecology. Progress in Obst and Gynaecol. 1996;12:215-33.

2. Table C-13, Single Year Age Returns by Residence and Sex: Census of India. 2011.

3. Goswami S, Dutta R, Sengupta S. A profile of adolescent girls with gynaecological problems.J Obstet Gynecol India. 2005;55:353-5.

4. Ramaraju HE, Shivakumar HC, Khazi AA. Adolescent gynaecological problems in a tertiary care centre. I Journal of Basic and Applied Medic Research. 2015;4:649-53.

5. Gandhi BA, Vaidya R, Bandi F. Managing Gynaecological problems in indian adolescent girls-a challenge of $21^{\text {st }}$ century. Obstet Gynaecol Int. 2015;3(1):00070.

6. Dangal G. Menstrual disorders in adolescents. Journal of Nepal medical association. 2004;43:15263.

7. Dutta DC, Konar H. Textbook of gynaecology. Kolkata, India: Central. 2007:504.

8. Goswami P, Ahirwar G, Mishra P, Agarwal V, Adolescent gynaecological problems: A prospective study. JEMDS. 2015;4(102):16709-12.

9. Kzlowski KJ. Ovarian masses. Adolesc Med. 1999;10:337-50.

10. Samarth S, Inamdar S, Hariharan C, Kalyani KR. Int J Repord Contracept Obstet Gynecol. 2014;3(4):1010-4.

11. Sönmez K, Türkyilmaz Z, Karabulut R, Demirogullari B, Özen IO, Moralioglu S, et al. Surgical breast lesions in adolescent patients and a review of the literature. Acta Chirurgica Belgica. 2006;106(4):400-4.

Cite this article as: Jain A, Singh D. Adolescent gynae clinic - need of the day: a prospective study at a tertiary care centre. Int J Reprod Contracept Obstet Gynecol 2019;8:1973-6. 